\title{
GAME RANCANG BANGUN KOTA SEDERHANA BERBASIS ANIMASI 2DIMENSI
}

\author{
Jimi Asmara \\ STIKOM Uyelindo Kupang, Nusa Tenggara Timur 85111 \\ jimmyasmara26@gmail.com
}

\begin{abstract}
ABSTRAK
Perkembangan dalam dunia game sangat pesat dimulai dari visualisasi gambar sampai dengan pergerakan objek gambar dari game tersebut. Terdapat 3 (tiga) jenis tampilan visualisasi game yang sekarang marak didunia hiburan terutama permainan game yaitu, 1 dimensi, 2, dimensi dan 3. Dengan memiliki jenis gambar sampai warna yang menarik untuk dimainkan. Dalam studi kasus berikut penulis akan membuat sebuah game dengan berbasis animasi 2 dimensi yang membutuhkan daya pikir, kecermatan, sampai imajinasi seorang pemain.Hasil yang diperoleh dari penelitian ini adalah untuk meningkatkan daya imajinasi pemain, merancang dan membangun sebuah pembangunan kota dengan material-material object yang telah ada sebelumnya, dengan penambahan bonus biaya pada saat bangunan kota telah dibangun yang bertujuan agar user dapat membeli material-material objek yang ada sesuai harga dan jumlah uang yang dikumpulkan oleh user dalam permainan game pembangunan kota berbasis animasi 2 dimensi.
\end{abstract}

Kata kunci:Animasi 2 dimensi, Game, Pembangunan Kota.

\section{PENDAHULUAN}

Dalam perkembangan komputer saat ini tidak hanya menjadi mesin hitung untuk aktifitas ketik mengetik dan sebagainya, tetapi semakin lengkap dengan fasilitas multimedianya sound dan aplikasi permainannya. Dengan berkembangnya komputer maka perkembangan perangkat kerasnya (hardware), terus dilakukan seperti pada processor, memory, media penyimpanan (harddisk), video graphics adapter (VGA), dan perangkat keras lainnya ini semua dilakukan guna menunjang aktifitas manusia yang serba instan dan cepat.

Seiring dengan perkembangan komputer maka aplikasinya pun ikut berkembang, diantaranya aplikasi game. Game juga merupakan salah satu basis ilmu yang berkembang seiring dengan perkembangan komputer game merupakan hal yang mudah untuk diperoleh tanpa membutuhkan biaya yang besar dan bisa memberikan sumber inspirasi. Teknologi game saat ini telah mampu menampilkan berbagai macam tampilan yang menarik untuk dimainkan, untuk menunjang itu semua maka perkembangan teknologi visual dan audionya yang digabungkan dengan multimedia, akan menghasilkan suatu game yang hidup sehingga para pemainnya (gamer) seolah-olah menjadi bagian dari game tersebut.

Perkembangan game juga saat ini telah terintegrasi dengan dunia internet, ini dibuktikan dengan adanya game-game online, semakin cerdasnya game dalam merespon, melakukan suatu tindakan simulasi atau strategi adalah bukti nyata dari perkembangan teknologi game. Rancang bangun kota sederhana adalah salah satu jenis game yang merancang tata letak kota secara sederhana sesuai dengan material yang telah disediakan seperti, 
bangunan gedung, rumah, taman, patung, jalan raya, dan sebagainya yang hanya bisa ditampilkan dengan tampilan 2 dimensi atau dengan tampak atas saja. Game rancang bangun kota sederhana ini dibuat untuk melatih kreatifitas, dimana pemain harus bisa membuat replika kota sederhana dengan material yang telah disediakan, melatih konsentrasi dan imajinasi sehingga terciptalah kota sederhana yang diinginkan oleh pemain (gamer). Game rancang bangun kota sederhana ini dibuat untuk semua kalangan mulai dari anak-anak, remaja, sampai dewasa bisa memainkan game ini.

\section{Rumusan Masalah.}

Berdasarkan permasalahan di atas, maka permasalahan yang diangkat adalah bagaimana merancang dan membangun suatu aplikasi game rancang bangun kota sederhana berbasis animasi 2 dimensi?

\section{Tujuan.}

Adapun tujuan dari penelitian yaitu:

a. Menghasilkan sebuah game yang menarik dan inovatif

b. Dapat menjadi panduan untuk pengembangan game sejenis kedepannya.

\section{Manfaat.}

Manfaat dari penelitian ini yaitu:

a. Untuk melatih kreatifitas user dalam membangun kota sederhana berbasis game.

b. Sebagai literatur untuk penelitian kedepannya.

Game pada dasarnya merupakan set instruksi kompleks yang dimasukkan ke program yang sudah memprediksi intelegensi pemakaiannya[1].

\section{Sejarah Game.}

Sejarah teknologi game komputer secara langsung berhubungan dengan perkembangan komputer itu sendiri. Komputer dengan kecepatan processor tinggi, grafis yang lebih mendekati realita, dan media penyimpanan yang lebih besar sebenarnya dimaksudkan untuk memenuhi kebutuhan dalam bermain games.Sebelum dimulai, akan kita pahami dulu apa arti dari game (game komputer). Game adalah sebuah permainan interactive yang membutuhkan komputer untuk bermain. Program komputer menerima input dari sipemain melalui pengendali dan menampilkan lingkungan buatan melalui TV atau layar monitor[1].

\section{Jenis Game.}

Jenis-jenis game biasanya dikenal dengan istilah ganre game. Ganre berarti format atau gaya dari sebuah game. Format sebuah game bisa murni sebuah ganre atau bisa merupakan campuran (Hybrid) dari beberapa ganre lain. Hal ini tidak salah dalam membuat suatu game. Pemain dapat menggabungkan beberapa ganre ke dalam sebuah game untuk membuat unsur permainan lebih bervariasi dan menantang [1].

Simulation Merupakan genre yang mementingkan realisme. Segala faktor pada game ini sangat diperhatikan agar semirip didunia nyata. Segala nilai, material, referensi, dan faktor lainnya adalah berdasarkan dunia nyata. Cara memainkannya juga berbeda, karena biasanya kontrol yang dimiliki cukup rumit. Genre simulasi meliputi game racing, flight, sampai militer[1].

Tycoon adalah game yang
menjadikan kita sebagai seorang
businessman yang akan mengembangkan
sesuatu Property untuk dikembangkan
hingga laku dipasaran[1].

Tycoon adalah game yang menjadikan kita sebagai- seorang businessman yang akan mengembangkan hingga laku dipasaran[1]. 
Tile Matching Game pada dasarnya menuntut pemain untuk fokus dalam mengidentifikasi pola- pola objek permainan sehingga menemukan aturan yang membuat objek tersebut dapat dieliminasi, memberikan point, dan mungkin dilakukan sebelum waktu atau kondisi selesai terpenuhi. Tantangan yang diberikan bisa dibedakan melalui variasi pola yang ada, jumlah tile/objek permainan, waktu yang diberikan, jumlah langkah dan lain-lain[5].

\section{Rancang Bangun Kota.}

Dalam Mulyandari (2010), Mumford menyatakan pengertian kota merupakan suatu pertemuan yang berorientasi keluar di mana kota merupakan daya tarik bagi penghuni luar kota untuk kepentingan perdagangan dan kerohanian [3].

\section{Pengertian 2 Dimensi.}

2dimensi atau biasa disingkat 2D, adalah bentuk dari benda yang memiliki panjang dan lebar [2]

\section{Sejarah Animasi.}

Animasi merupakan suatu seni untuk membuat dan menggerakkan sebuah obyek, baik berbentuk 2 dimensi maupun 3 dimensi dan dibuat menggunakan berbagai cara, misalnya menggunakan kertas, komputer dan lain sebagainya. Animasi saat ini telah menjadi industri besar yang memberikan dampak ekonomi dan sosial yang begitu besar bahkan cukup signifikasi terhadap pendapat sebuah Negara[4].

\section{METODOLOGI PENELITIAN}

Pendekatan yang dilakukan pada penelitian ini adalah dengan metode penelitian pengembangan research dan developmen yaitu metode penelitain yang digunakan untuk menghasilkan produk dengan menguji keefektifav produk.adapun tahapan yang dilakukan adalah analisis kebutuhan, rancang desain, implementasi desain, pengujian, perbaikan dan produk. Seperti yang tampak pada gambar 1 .

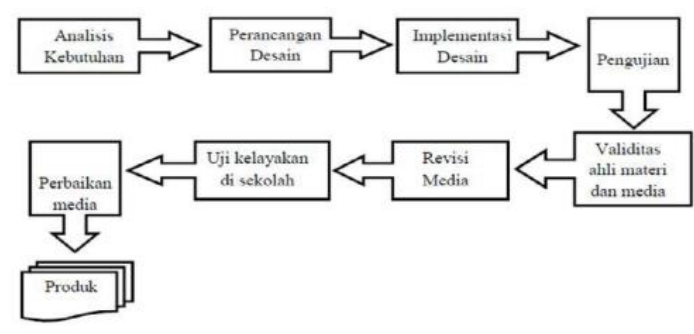

Gambar 1. Metodologi penelitian

\section{HASIL DAN PEMBAHASAN}

Kebutuhan sistem. Berikut adalah penjelasan berbagai hal mengenai software yang digunakan dalam membangun aplikasi game rancang bangun kota sederhana berbasis animasi 2 dimensi

Microsoft Visual Basic 6.0 merupakan subuah bahasa pemograman komputer yang berjalan pada sebuah sistem windows. Bahasa pemograman adalah sekumpulan perintah atau instruksi yang dimengerti oleh komputer untuk mengerjakan tugas-tugas tertentu.Visual Basic 6.0 dapat menghasilkan tipe data yang dapat disesuaikan sendiri. Tipe data tersebut dapat berupa argumen dan properti. Dengan adanya fasilitas Native Code untuk mengkompilasikan source code, maka akan menghasilkan suatu aplikasi dengan waktu eksekusi lebih cepat. Visual Basic 6.0 menyediakan tiga macam.interface yang bisa digunakan untuk merancang aplikasi sesuai dengan kebutuhan. Interface tersebut berupa MDI (Multi Document nterface), SDI (Single Document Interface) dan EDI (Explore Document Interface). Modifikasi pada masing-masing bagian akan terasa lebih mudah. Fasilitas yang disediakan juga lebih lengkap sehingga bisa memenuhi selera programmer yang pada akhirnya akan meningkatkan produktivitas kerja. 


\section{Kebutuhan Perangkat Keras}

Intel(R) Core(TM) 2 Duo CPU

T6660@2.20GHz (2 CPUs).RAM SingleChannel DDR2 @ 399MHz (5-5-5-18) 1916 MB.Hard Disk Hitachi HTS545032B9A300 (SATA) 350 GB. Mouse Micro Pack USB dan Keyboard.

Kebutuhan Perangkat Lunak.

Sistem operasi Microsoft Windows XP Professional.Microsoft Office word 2007.Microsoft access 2007.Microsoft Office Visio 2003. Microsoft Visual Basic 6

Berikut perancangan sistem dan tampilan program dari game rancang bangu $\mathrm{n}$ kota berbasis animasi 2dimensi

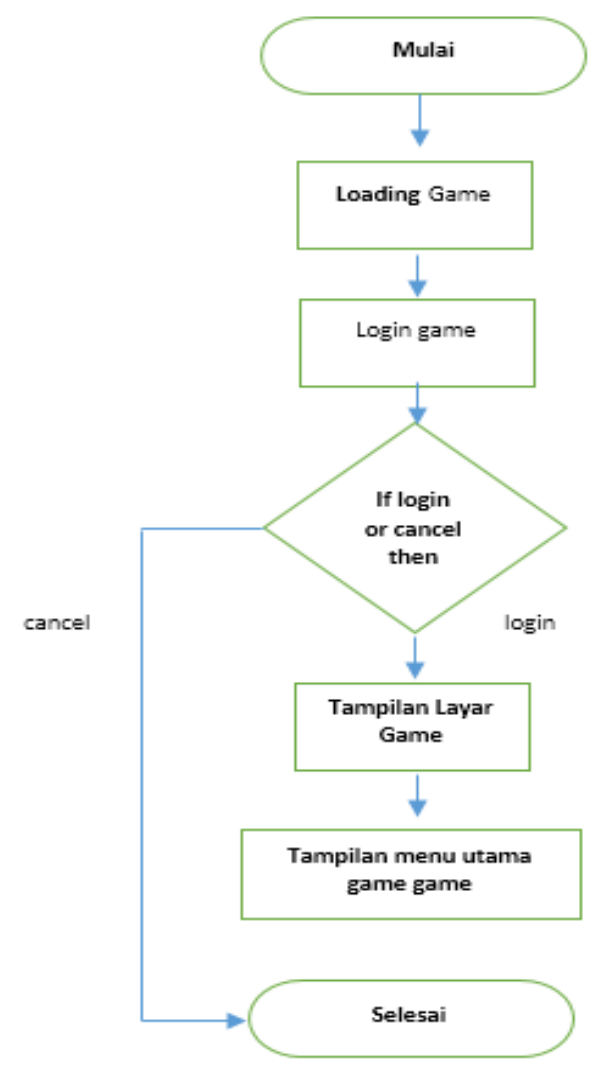

Gambar 2. Diagram alur proses Permainan Game

Dari penjelasan alur flowchart diatas menjelaskan, dari simbol terminal yang merupakan awal mulai menjalankan aplikasi yang kemudian masuk ke menu loading, setelah proses loading selesai masuk ketampilan menu loggin user, jika batal maka selesai dan jika berhasil loggin maka ke tampilan rancang bangun kota.

\section{Tampilan Program}

Menu loading Pada tampilan menu loading akan muncul pertama kali saat user melakukan klik pada file *.exe program dan melakukan proses loading untuk tampil ke form login user.

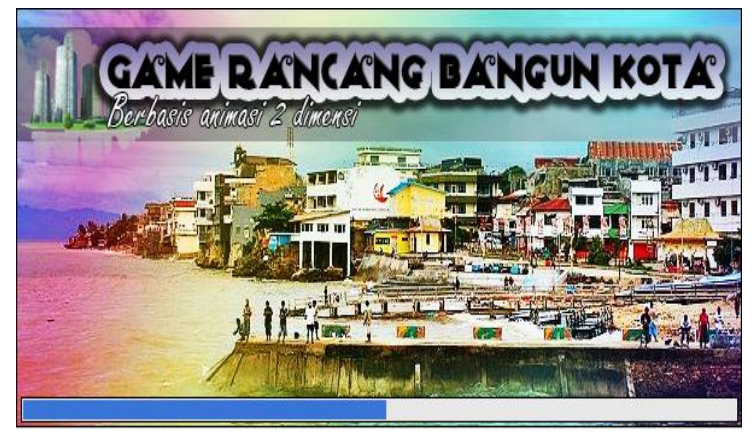

Gambar 3. Menu loading.

Dalam menu login terdapat tiga (3) menu pilihan yaitu, login user untuk mamasukan nama atau kode user beserta password user pada textbox yang ada, kemudian menekan tombol masuk untuk ke menu pilihan permainan dan tombol keluar untuk membatalkan login. Menu buat user baru untuk membuat user baru kedalam database agar setiap login masuk bisa berdasarkan user yang berbeda-beda, dan menu terakhir adalah menu keterangan yang berisikan keterangan tentang aplikasi game rancang bangun kota sederhana berbasis animasi 2 dimensi.

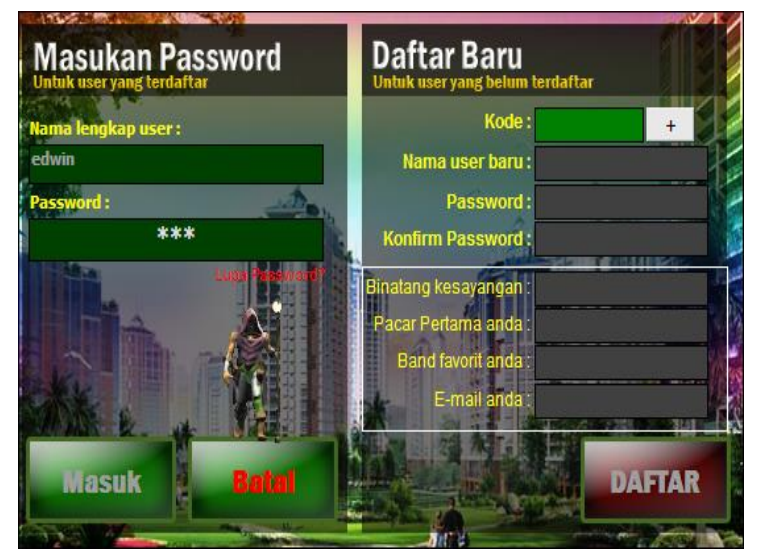

Gambar 4. Menu login. 
Dalam menu mulai ini memberikan dua (2) tombol proses yaitu tombol mulai untuk masuk ke menu utama dan tombol keluar untuk keluar aplikasi, dan menampilkan nama pembuat, tempat kuliah jenis program aplikasi untuk membuat aplikasi rancang bangun kota.

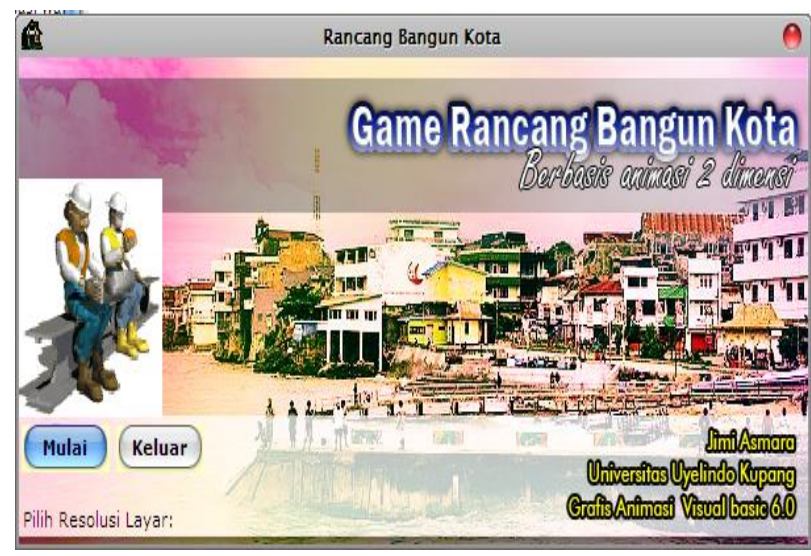

Gambar 5. Menu mulai.

Menu utama dengan tampilan seperti yang terlihat pada gambar 6 , dalam form ini awalnya akan menampilkan layar kosong atau dataran rumput hijau yang berbentuk persegi empat dimana dalam tampilan tersebut user akan melakukan tata letak kota sesuai keinginan diatas dataran rumput tersebut dengan menu materialmaterial pembangunan yang ada berupa material jenis-jenis perkantoran, rumah kecil, rumah kota, bangunan biasa, pohon, air mancur, jalan raya dan patung.

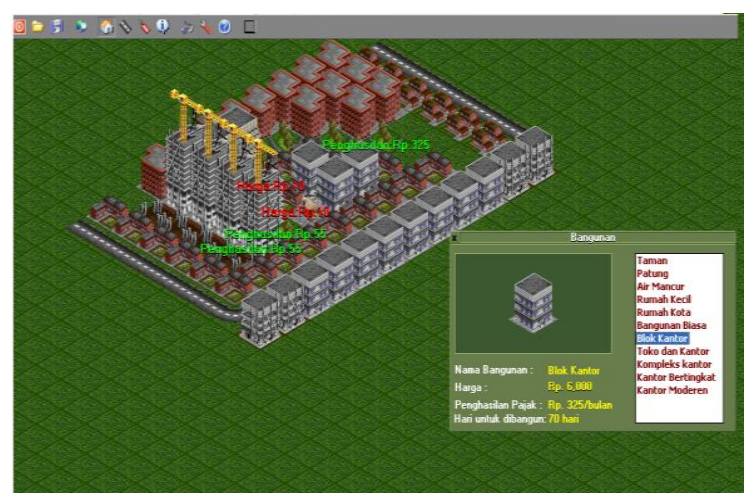

Gambar 6. Tampilan Menu Utama Game.
Tampilan menu konstruksi pembangunan berfungsi untuk memilih material-material pembangunan seperti rumah, perkantoran, taman dan patung untuk diletakkan pada layar kerja menu utama.

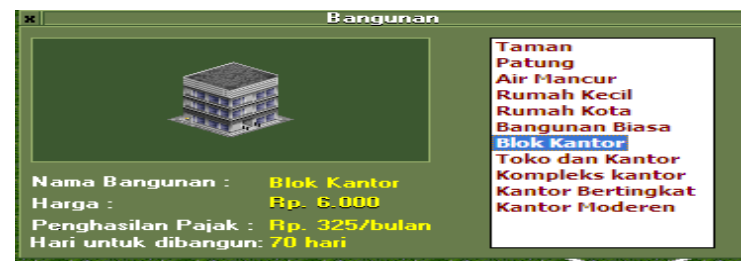

Gambar 7. Menu konstruksi.

Tampilan menu jalan raya digunakan dalam meletakkan jalan raya dalam media kerja di menu utama. Gambar jalan raya memiliki banyak bentuk percabangan sehingga akan membentuk jalan raya dengan banyak jalur yang akan mengelilingi layar kerja pembangunan

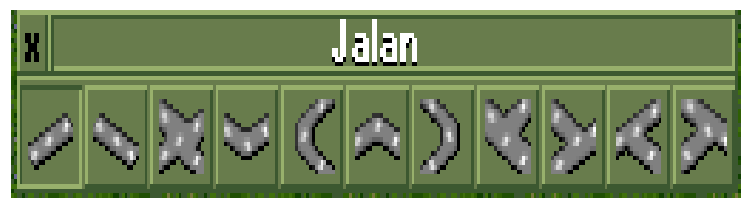

kota.

Gambar 8. Menu jalan raya.

Tampilan menu musik, bertujuan agar user saat membuat game pembangunan kota, bisa menikmati dan mendengar musik sesuai keinginan.

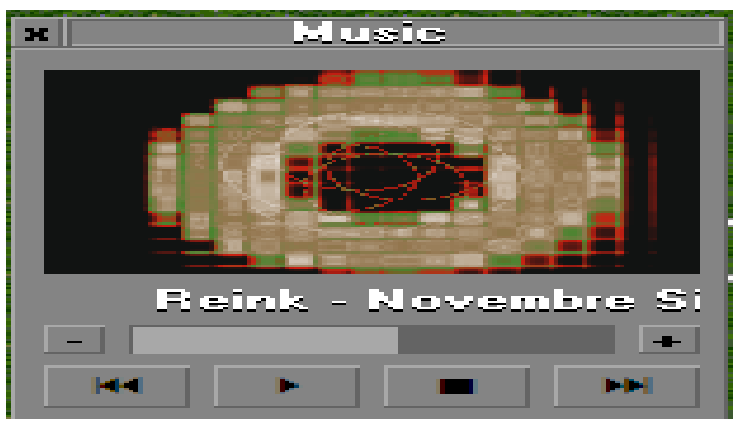

Gambar 9. Menu musik. 
Menu setting berguna untuk menampilkan jarak-jarak penempatan material dengan koordinasi sumbu $\mathrm{X}$ dan $\mathrm{Y}$ yang ingin diletakkan pada ruang kerja pada layar menu utama.

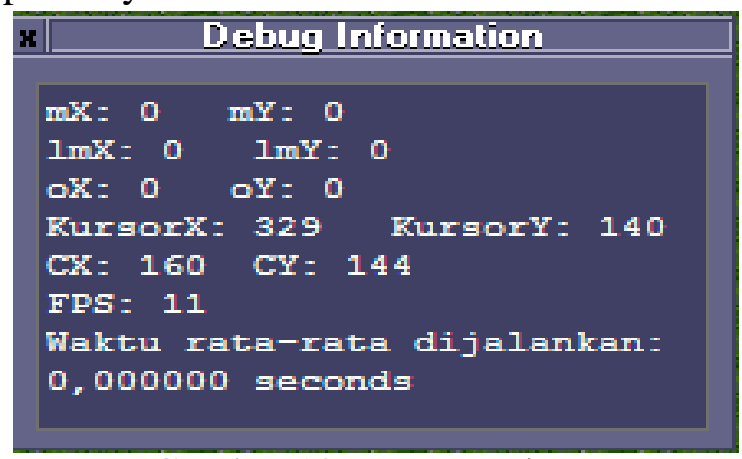

Gambar 10. Menu setting

Menu informasi material berfungsi manampilkan keterangan informasi meterial-material yang akan di letakkan di dalam layar project utama aplikasi.

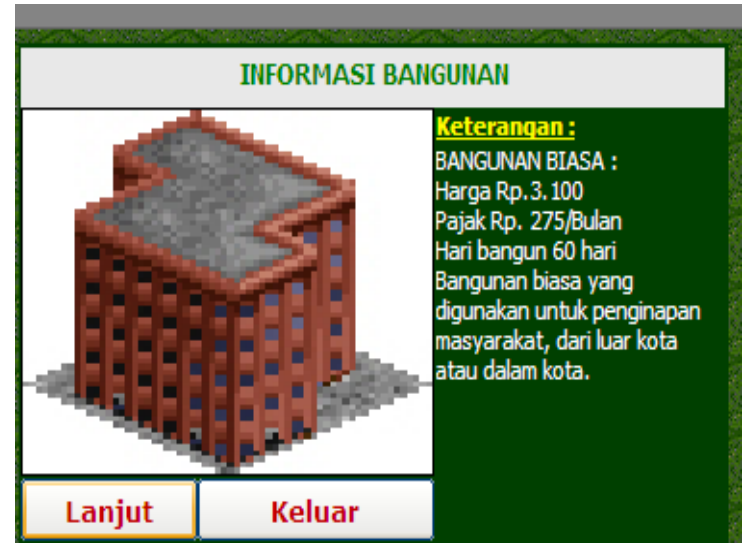

Gambar 11. Menu Informasi.

Menu about berguna untuk menampilkan keterangan user didalam aplikasi rancang bangun kota berbasis animasi 2 dimensi.

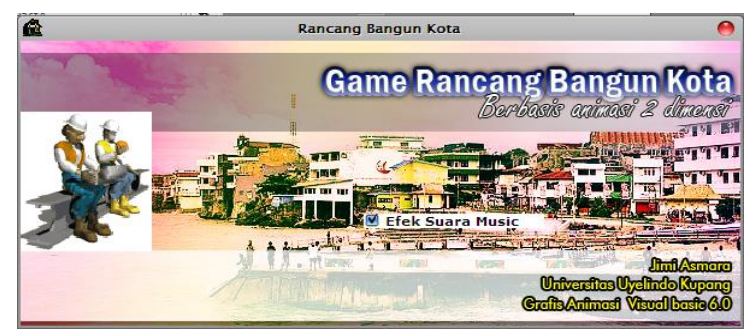

Gambar 12. Menu About.

\section{KESIMPULAN.}

Program game rancang bangun kota sederhana berbasis animasi 2 dimensi merupakan aplikasi permainan yang dibuat untuk para pemain (gamer) dapat dimainkan dengan cara meletakkan material-material objek pada bidang layar kerja di menu utama, yang dapat menambah kreatifitas dan daya imajinasi seorang gamer.

Dari hasil uraian yang telah dikemukakan diatas, maka penulis dapat memberikan kesimpulan dalam penelitian ini yaitu:

a. Pemanfaatan teknologi komputer dalam pemrograman pembuatan aplikasi permainan (game) rancang bangun kota berbasis 2 dimensi, agar dapat dimainkan oleh berbagai kalangan masyarakat luas khususnya peminat aplikasi game.

b. Dengan adanya aplikasi game rancang bangun kota sederhana Dapat melatih kemampuan imajinasi dan kreatifitas seseorang dalam membangun sebuah kota sederhana, sehingga tampilan hasil yang diinginkan bisa dinikmati dengan efek animasi 2 dimensi, dengan beberapa material-material objek yang ada seperti taman, patung, air mancur, rumah kecil, rumah kota dan sebagainya.

c. Aplikasi game rancang bangun kota adalah jenis game yang tidak membutuhkan koneksi internet untuk menjalankannya atau game stand alone.

\section{Saran}

Dalam kesempatan ini penulis akan menyampaikan beberapa saran yang sekiranya berguna bagi para pembacanya guna mengembangkan aplikasi ini lebih lanjut diantaranya adalah: 
a. Agar aplikasi game rancang bangun kota sederhana berbasis animasi 2 dimensi ini dapat berjalan sesuai dengan harapan, bagi pengguna aplikasi rancang bangun kota ini dapat menginstal software visual basic 6.0 kedalam media komputer.

b. Dengan adanya game ini diharapkan dapat menjadi referensi dan pembanding untuk penelitianpenelitian berikutnya agar dapat dikembangkan lebih baik lagi kedepannya.

c. Pengembangannya tidak hanya bangunan, arsitektur tetapi keseluruhan kota agar bisa meningkatkan kreatifitas dan dibuat dengan teknik 3 dimensi.

d. Aplikasi game ini diharapkan bisa dikembangkan menggunakan bahasa pemograman lainya, misalnya : $C++$, Foxpro, java, delphi, dan bahasa pemograman yang bisa membuat aplikasi game yang ada.

\section{DAFTAR PUSTAKA}

[1] Baskoro, Wahyu, "Kamus Besar Bahasa Indonesia", Edisi 3 Departemen pendidikan nasional balaipustaka, 2003.

[2] Dea Bulan Sagitha, "Rancang Bangun Aplikasi Game 2d Merapikan Kamar Tidur" Fakultas Ilmu Komputer Program Studi Teknik Informatika-S1 Universitas Dian Nuswantoro Semarang

[3] Dr. Suyoto, "Intelegensi Buatan Teori dan pemograman", Edisi Pertama, GAVA MEDIA, 2004.
[4] Mulyandari, Hestin "Pengantar Arsitektur Kota", Penerbit Andi Yogyakarta, 2010.

[5] Koswara, Eko "Visual Basic 6.0.", penerbit Mediakom, Yogyakarta, 2011.

[6] Sudarmono, Padji "Kamus Istilah Komputer dan Teknologi Informasi Komunikasi”, penerbit Yrama Widya, Bandung, 2006. 